\title{
MODOS DE ESCUCHA EN MÚSICA Y EN PSICOANÁLISIS ${ }^{1}$
}

\author{
Modes of listening in music and in psychoanalysis
}

\author{
Olga Picún ${ }^{2}$ \\ Ana María Fernández Caraballo ${ }^{3}$
}

\begin{abstract}
RESUMEN
En la larga historia de la música occidental, cuyo antecedente directo se suele ubicar en la antigua Grecia, el oyente y la escucha han experimentado múltiples cambios. Determinantes históricos, sociales y políticos, que exceden el campo específicamente musical, subyacen al modo de escuchar. No obstante, las transformaciones musicales resultan ineludibles para aproximarse a una comprensión de los cambios que se producen en el oyente y en el acto de oír una obra musical.

En este trabajo una serie de preguntas guían el análisis y las reflexiones. ¿De qué modo se producen las transformaciones sonoras en el Modernismo y cómo afectan la escucha? ¿Qué lugar ha tenido la música y la dimensión de lo sonoro para el psicoanálisis (Freud y Lacan)? Y, ¿qué relaciones se pueden establecer entre dichas transformaciones y el psicoanálisis?
\end{abstract}

Palabras clave: consonancias, disonancias, música, psicoanálisis.

${ }^{1}$ Este artículo es producto de la Línea de investigación «Música, psicoanálisis y educación» dirigida por la Dra. Olga Picún y la Dra. Ana María Fernández Caraballo (FIC y FHCE, Udelar). Como antecedente de investigación cuenta con el artículo «Relaciones entre música y psicoanálisis: escucha y escritura de casos» de Ana María Fernández Caraballo publicado en Fermentario, 9(2), 2015, revista del Instituto de Educación, Facultad de Humanidades y Ciencias de la Educación, Universidad de la República. www.fhuce.edu.uy; Faculdade de Educação, UNICAMP, www.fe.unicamp.br; Centre d'Études sur l'Actuel et le Quotidien, Sorbonne, www.ceaq-sorbonne.org. Ver en bibliografía: Fernández Caraballo, 2015.

${ }^{2}$ Universidad de la República (Udelar). Prof. Adjunta del Departamento de Teoría y Metodología del Instituto de Comunicación de la Facultad de Información y Comunicación. Uruguay.

Correo electrónico: olga.picun@fic.edu.uy

${ }^{3}$ Universidad de la República (Udelar). Prof. Titular del Departamento de Enseñanza y Aprendizaje del Instituto de Educación de la Facultad de Humanidades y Ciencias de la Educación. Uruguay.

Correo electrónico: amfernandezcaraballo@gmail.com

Recepción: 25/6/2018Ａceptación: 10/3/2019 


\begin{abstract}
In the long history of Western music, whose direct antecedent is usually located in ancient Greece, the listener and the listening have experienced multiple changes. Historical determinants, social and political, that exceed the specifically musical field, underlie the way of listening. However, the musical transformations are inescapable to approach an understanding of the changes that occur in the listener and in the act of hearing a musical work.

In this work a series of questions guide the analysis and reflections. How are the sound transformations in modernism produced and how do they affect listening? What place has music and the dimension of sound for psychoanalysis (Freud and Lacan)? And, what relationships can be established between these transformations and psychoanalysis?
\end{abstract}

Key Words: consonance, dissonance, music, psychoanalysis.

\title{
Importancia de la dimensión sonora para el psicoanálisis
}

La función de la música se muestra irreductible a todo aquello que sería posible de traducir bajo la forma verbal. Ella se ejerce debajo de la lengua y de cualquier discurso, a pesar de que emane del comentarista más inspirado, no será lo bastante profundo para explicitarla. (Levi-Strauss, 1976, p. 112).

La música viola el cuerpo humano. Lo pone de pie. Los ritmos musicales suscitan los ritmos corporales. La oreja no se puede cerrar cuando se encuentra con la música. Al ser un poder, la música se asocia a todo poder. Es esencialmente desigual. Oír y obedecer van unidos (Obaudire). (Quignard, 1998, p. 191).

Comencemos con la siguiente pregunta básica, pero esencial, para nuestra reflexión: ¿por qué un determinado modo ${ }^{4}$ musical o determinados intervalos ${ }^{5}$ musicales producen efectos consonantes y otros disonantes? Como es bien sabido, la distinción entre consonancia y disonancia está presente desde los antiguos griegos con relación al modo musical apolíneo (modo dórico) y al dionisíaco (modo frigio). ${ }^{6}$ Sin embargo, ha adquirido diferentes significados en el contexto de la tonalidad, en la que dicha oposición se aplica a los intervalos. Entonces, ¿cuál es la censura social

${ }^{4}$ En términos muy sencillos se puede decir que un modo musical es una sucesión de sonidos por grados conjuntos, los cuales guardan ciertas relaciones interválicas consecutivas. Los sistemas modales se utilizaron en la música griega antigua y en la medieval (modos gregorianos); se observan en la música de tradición popular de Occidente y también en culturas no europeas.

5 Se denomina intervalo a la diferencia de altura o frecuencia entre dos sonidos, sean superpuestos o consecutivos. Los intervalos consonantes en la música tonal son: unísono, terceras y sextas mayores y menores, quintas y octavas justas; mientras que los demás se consideran disonantes.

${ }^{6}$ Al respecto ver: Nietzsche, 1973 y también el trabajo que realiza Didier-Weill, 1999. 
que se encuentra desde Aristóteles y que ha generado tanto el rechazo a la música dionisíaca de entonces como a la música calificada de «atonal» a comienzos del siglo XX?

En la historia de la música occidental, cuyo antecedente directo se suele ubicar en la Grecia antigua, el oyente y la escucha han pasado por variadas modificaciones. Es posible afirmar que la ley que gobierna un estilo de escucha se encuentra atravesada por determinaciones históricas, políticas, sociales que sobrepasan el campo específicamente musical. No obstante, las transformaciones musicales resultan ineludibles para aproximarse a una comprensión de los cambios que se producen en el oyente y en el acto de oír una obra musical. Más aún en contextos como el Modernismo, que desde diferentes concepciones estéticas vulnera una parte sustancial de la identidad del sistema tonal, cuya hegemonía definió el universo simbólico occidental durante más de dos siglos. Además, no debemos dejar de señalar inconvenientes que se revelan al querer expresar algo respecto de los efectos que produce la escucha de cualquier obra musical.

Esto tal vez se debe a la dificultad específica de la música que tiene la particularidad de estar alejada de la representación. ${ }^{7}$ Recordemos las apreciaciones de Hegel (1991) en su libro Estética II, en el capítulo «Sobre la música» cuando señala sus rasgos característicos: fuera de toda representación, de una modalidad fugitiva y negativa a la vez, se entreteje «en» $\mathrm{y}$ «con» el silencio. (Fernández Caraballo, 2015, p. 3).

Ahora bien, ¿qué lugar ha tenido la música y la dimensión de lo sonoro para el psicoanálisis (Freud y Lacan) $?^{8}$ Uno de los puntos fundamentales a resaltar es la importancia de la relación entre la pulsión invocante y la música. Al respecto afirma Didier-Weill (1999):

La vocación de hacernos humanos nos es transmitida, en el origen, por una voz que no nos pasa la palabra sin pasarnos al mismo tiempo su música: el lactante recibe la música de esa «sonata materna» como un canto que, de entrada, transmite una doble vocación: ¿escuchas la continuidad musical de mis vocales y la discontinuidad significante de mis consonantes? (p. 7).

7 Sobre esta temática ver: Fernández Caraballo, 2010.

8 Sobre esta pregunta hemos insistido, también, en Fernández Caraballo, 2015 y Villalba y Fernández Caraballo, 2012. 
Por su parte, en El odio a la música, Pascal Quignard (1998) entiende que «no podemos no oír», mucho antes de poner en ejercicio la mirada, el niño es sometido a los sonidos en donde la audientia es una obaudientia. ${ }^{9}$ El sonido no se emancipa nunca del todo de un movimiento del cuerpo que lo causa y lo amplifica, es la obediencia materna.

El vínculo entre la madre y el niño y la adquisición de lenguaje se forman en el seno de una incubación sonora. El ruido del mundo es percibido como un ronroneo sordo, dulce y grave sobre el cual se eleva la voz de la madre, base de la melodía. El sonido toca al instante el cuerpo. Ante lo sonoro, el cuerpo, más que desnudo, está desprovisto de piel. Las orejas no tienen prepucio ni párpados. Durante la audición somos reclusos. El sonido es un perforador de coberturas, ya que no sabe lo que es un límite, no es interno ni externo. La audición no es como la visión, que puede ser cancelada por el uso de los párpados, o por un tabique. Nada hay en lo sonoro que nos retorne una imagen localizable, simétrica e invertida de nosotros mismos, como lo hace el espejo. El eco no es exactamente un objectus, no es un reflejo arrojado ante el hombre: es una reflexión sonora y quien la oye no se acerca sin destruir su efecto. No hay espejo sonoro donde el emisor se contemple. (Quignard, 1998, p. 104).

Por otra parte, en Freud y en Lacan el lugar que adquirió la música y lo sonoro fue altamente diverso. Señalaremos algunos ejemplos a modo de muestra. En «El Moisés de Miguel Ángel», Freud (1914) subraya la atracción que le generaban las obras de arte: «uno las admira, se siente subyugado por ellas, pero no sabe decir qué representan» y añade que la escultura, la poesía y en menor grado la pintura le producen un «poderoso influjo». Sostiene que «ello me ha movido a permanecer ante ellas durante horas cuando tuve oportunidad, y siempre quise aprehender a mi manera, o sea, reduciendo a conceptos, aquello a través de lo cual obraban sobre mí de ese modo» (Freud, 1914, p. 217).

Sin embargo, sobre la música indica algo radicalmente diferente:

Cuando no puedo hacer esto — como me ocurre con la música, por ejemplo-, soy casi incapaz de obtener goce alguno. Una disposición racionalista o quizás analítica se revuelve en mí para no dejarme conmover sin saber por qué lo estoy, y qué me conmueve. (Freud, 1914, p. 217).

\footnotetext{
${ }^{9}$ Oír deriva del latín audire, palabra de la que deriva, a su vez, oboedire, 'obedecer'.
} 
Para Lacan, la música y la dimensión de lo sonoro adquiere, sin embargo, un lugar relevante, incluso hay señalamientos que recorren gran parte de su obra. A modo de ejemplo, en su Seminario Aun, propone que «el Barroco es la regulación del alma por la escopia corporal». Es decir, que si se separa la música del campo escópico se la coloca del lado de la pulsión invocante. Es más, plantea que

Habría que hablar de la música al margen. Por lo tanto, solamente hablo de cuanto se ve en todas las iglesias de Europa, cuanto se cuelga en las paredes, se desmorona, deleita, delira. Lo que hace un rato llamé «obscenidad», pero exaltada. (Lacan, 1972-1973, p. 101).

Está haciendo referencia a que la música es, también, una manera de tratar el vacío.

Algo de eso se encuentra en el Barroco en su característica de llevar al límite el trabajo con el sonido en detrimento del silencio. Se trata del horror vacui ${ }^{10}$ el cual consiste en llevar el ornamento hasta el extremo, el cual se muestra y se exhibe, hasta el punto de ser calificado por Lacan como «obsceno». (Fernández Caraballo, 2015, p. 6).

En el artículo «L'émancipation de la dissonance. A propos du Cas Schönberg d’Esteban Buch», François Dachet (2008) aborda los efectos subjetivos y sociales que puede generar la música. Se basa en el libro de Esteban Buch (2006), Le cas Schönberg, quien se detiene a estudiar de forma profunda el «escándalo que suscitó la composición atonal de Schönberg y su relación con la Viena de Freud», además de las relaciones entre músicos y psicoanalistas. Ahora bien, ¿de qué modo en el Modernismo se plantean transformaciones en la producción musical y cómo éstas afectan la escucha?

${ }^{10}$ La expresión latina horror vacui (miedo al vacío) se emplea en la historia del arte para describir el relleno de todo espacio vacío en una obra de arte con algún tipo de diseño o imagen. Es característico de la estética del Barroco y especialmente del Rococó, así como en la decoración islámica y en el lujo ostentoso del arte bizantino. 


\section{Modernismo musical y desafíos en la escucha: Schönberg y Freud}

En la transición del siglo XIX al XX se producen cambios importantes en el pensamiento artístico de Occidente que se instalan en el Modernismo. La inexistencia de una solución de continuidad con las dinámicas de sucesión de los diferentes estilos artísticos es el aspecto sustancial de este quiebre, en la medida en que el Modernismo no necesariamente constituye una reacción en contra del Romanticismo, sino en contra de una concepción del arte que había dominado durante varios siglos. Al respecto, señala Arthur Danto (1999) que el Modernismo

... está marcado por el ascenso a un nuevo nivel de conciencia, reflejado en la pintura como un tipo de discontinuidad, como si acentuar la representación mimética se hubiera vuelto menos importante que otro tipo de reflexión sobre los sentidos y los métodos de representación. (p. 30).

La nueva conciencia surge de un ejercicio de autocrítica no solo en el ámbito de las artes, sino de las ciencias, la filosofía, etc., (Danto, 1999).

En música, ese nivel de conciencia adquiere su máxima expresión en la disolución de la tonalidad, como sistema jerárquico de organización de los sonidos en estrecho vínculo con el componente formal. Este sistema atraviesa los diferentes estilos que se desarrollan en el mundo occidental desde el último cuarto del siglo XVI hasta finales del siglo XIX. Las transformaciones que se experimentan en cada periodo surgen de transgredir en alguna medida las normas que lo rigen, pero sin perder su identidad. El reconocimiento de esta identidad asociada a esas transgresiones o «desvíos»—-según denominación de Kröpfl (2006) — es lo que permite al receptor situarse en un contexto estético particular.

El sistema tonal se basa en un conjunto de relaciones dialécticas, entre otras: tensión-distensión, consonancia-disonancia. Cada oposición está definida por un vínculo de dependencia de uno de los componentes: la tensión se encuentra supeditada a la distensión, mientras que la disonancia a la consonancia; tanto la distensión como la consonancia funcionan como puntos de confluencia. 
Dentro de este sistema, caracterizado por la direccionalidad discursiva, cada sonido o grado de una escala temperada ${ }^{11}$ mayor o menor corresponde a la nota fundamental de una tríada ${ }^{12}$ que podrá tener, según un orden jerárquico, función de tónica, dominante (quinto grado y séptimo grado alterado o sensible) o de subdominante (segundo, cuarto y sexto grado). De esta manera la tensión generada por un acorde con función dominante implica una resolución en el de tónica, como único punto posible de reposo armónico o distención.

Debido a la redundancia de este sistema y al vínculo armónico-estructural — que funciona jerárquicamente frente al resto de los parámetros musicales (melodía, ritmo, timbre, entre otros)-, un escucha competente en la música occidental de la época contaría con elementos referenciales suficientes tanto para ubicarse en la estructura de una obra como para «predecir»—considerando los límites que impone la creatividad - su evolución y su final. Por lo tanto, el abandono de la tonalidad supone, en términos estratégicos, vulnerar en alguna medida el conjunto de relaciones jerárquicas que la sustentan, lo que exige al escucha el desarrollo de nuevas capacidades o competencias, acordes a los diferentes modos de trascender el sistema tonal, de los cuales se abordan con intención dialógica: la música de Claude Debussy y la Segunda Escuela de Viena. ${ }^{13}$

El proceso de transformación comienza en pleno Romanticismo, cuando Chopin, Liszt y Wagner ${ }^{14}$ introducen mecanismos de expansión de la tonalidad y de quebrantamiento de la correspondencia entre la función armónica y las formas tradicionales. ${ }^{15}$ Juega un papel importante

\footnotetext{
11 Cuya afinación se fija a partir de un la de 440 Hertz.

12 Acordes que se forman mediante la superposición de dos terceras. Por ejemplo: do, mi, sol.

13 La Primera Escuela de Viena la integran Mozart, Beethoven y Haydn.

14 Cabe aclarar que este camino hacia la atonalidad no se enmarca en un movimiento musical, sino que se caracteriza por la influencia de un compositor a otro, como es el caso de Chopin a Wagner, y de este último a Debussy.

15 No obstante, en el preludio del oratorio La creación (1798) Joseph Haydn lleva al extremo el cromatismo y la disonancia.
} 
en este sentido el empleo de estrategias para retardar o evitar el reposo, como la exacerbación del cromatismo, ${ }^{16}$ los acordes sin resolución y la enarmonía, que permite cambiar de contexto armónico en el transcurso de una obra; también la introducción de escalas foráneas al sistema tonal, la composición de piezas breves o en un solo movimiento que no responden a las estructuras afianzadas en el clasicismo, o la discursividad excesivamente prolongada. La combinación selectiva de estos u otros recursos que comprometen los componentes armónicos y formales de la tonalidad, debilitándola o rompiéndola, definen los diversos caminos estéticos o estilísticos que se emprenden a comienzos del siglo XX, cuyo sustento ideológico se expresa en ocasiones a través de manifiestos, adquiriendo de esta manera un carácter de movimiento artístico.

Claude Debussy es, según Pierre Boulez, quien propone en el aspecto estructural una ruptura completa con la tradición. Si bien su estética suele ser asociada fundamentalmente al impresionismo, existe un matiz entre el significado que la obra de Debussy tiene para la historia de la música y el que dicha corriente estética adquiere para la historia del arte. La aproximación estética del compositor francés al Simbolismo literario, así como al decadentismo, se observa incluso en los referentes de parte de su obra: Prélude à l'aprés-midi d'un faune (1892-1894) sobre un poema de Stéphane Mallarmé; la ópera Pelléas et Mélisande (estreno: 1902) basada en la pieza teatral homónima de Maurice Maeterlinck; las canciones sobre poesía de Paul Verlaine o Charles Baudelaire, entre otros. A diferencia de lo que ocurre con Debussy, con relación al Modernismo, el impresionismo pictórico es considerado un antecedente contra el que reacciona el expresionismo, como movimiento verdaderamente vanguardista. Es reveladora de esta diferenciación la

16 Ver nota 19. 
correspondencia que Boulez establece entre Debussy, Anton Webern y Mallarmé, en el siguiente fragmento de su «Incipit» $\mathrm{u}$ «Homenaje a Webern» $(1952):{ }^{17}$

En efecto, solo Debussy puede aproximarse a Webern en una misma tendencia a destruir la organización formal preexistente en la obra, en un mismo recurrir a la belleza del sonido por sí mismo, en una misma pulverización elíptica del lenguaje. Y sí es posible afirmar —oh Mallarmé-, que Webern estaba obsesionado por la pureza formal hasta en el silencio, él llevó esta obsesión a un grado de tensión que, hasta ese entonces, la música desconocía. (Boulez, 1952, en De Assis, 2012, p. 45).

En Debussy, la construcción de secciones de diferente longitud no responde a una forma predeterminada dependiente del movimiento tonal, sino que aparece asociada a cambios de atmósfera. Esta ruptura se consolida al combinarse con el debilitamiento de la tonalidad, producido mediante estrategias generadoras de ambigüedad, tales como: la construcción de una obra en planos superpuestos independientes, o sea, en ámbitos diatónicos diferentes, que puede ser escuchada como politonalidad; la desfuncionalización tonal a través del paralelismo de acordes o el empleo de modos gregorianos medievales, escalas pentatónicas ${ }^{18}$ o escalas de tonos enteros; ${ }^{19}$ el uso de cromatismos o del total cromático entre los distintos planos, o la densificación rítmica que produce «manchas sonoras» con la consecuente pérdida de la sensación de pulso y de la relación consonancia-disonancia. La vulneración de las tensiones que comparte el uso de estas estrategias atenta contra la direccionalidad discursiva del sistema tonal y se percibe como una tendencia al estatismo.

${ }^{17}$ Este escrito fue publicado en varias oportunidades, bajo diferentes títulos y en distintos idiomas. La versión original apareció en el New York Herald Tribune en 1952, con el título «Note to tonight's concert: Webern's works analysed» (De Assis, 2012, p. 45).

${ }^{18}$ Los modos medievales y las escalas pentatónicas carecen de nota sensible (séptimo grado alterado).

${ }^{19}$ La escala de tonos enteros y la escala cromática tienen en común que todos sus intervalos consecutivos son iguales, por lo tanto, no se producen jerarquías entre los sonidos que las conforman. En el primer caso, la distancia entre dos sonidos es de un tono, mientras en el segundo es de un semitono. El intervalo de semitono se denomina cromático o cromatismo. 
En los años cincuenta el musicólogo español radicado en México, Adolfo Salazar, se expresaba sobre el rompimiento de la tensión consonancia-disonancia y el estatus que adquiere el color tímbrico en la música del compositor francés:

Así, en Debussy el sonido vale por sí propio: la disonancia es un valor, como la consonancia puede serlo, más no una con relación a la otra; el timbre es otro valor que ha trascendido a la jerarquía que antes tenía la tónica y alrededor de la cual se ordena toda la obra con una lógica que escapa al análisis, pero cuya sensación satisfactoria se acusa en la conciencia. (Salazar, 1954; en García Laborda, 2004, p. 11).

La Segunda Escuela de Viena, que encabezan Arnold Schönberg y sus discípulos Anton Webern y Alban Berg, propone otro de los múltiples caminos estéticos del modernismo musical, parte de él asociado al expresionismo alemán. Desarrollado en sus comienzos por dos colectivos de artistas plásticos, Die Brücke —El Puente—(Dresde, 1905-1913) y Der Blaue Reiter —El Jinete Azul— (Berlín, 1911-1914), el expresionismo no aspira a representar la realidad, sino la percepción que de esta tiene el artista.

El proceso creativo de Schönberg, que culmina en el rigor del serialismo o método dodecafónico, surge de llevar al extremo los principios del Romanticismo. Desde una perspectiva postromántica, caracterizada por una discursividad prolongada - cuyo referente es Gustav Mahler-, Schönberg se enfoca en explorar la tonalidad hasta las últimas consecuencias, definiendo entre 1909 y 1916 su etapa atonal libre, ${ }^{20}$ que constituye el germen del serialismo dodecafónico.

En él [Schönberg], el momento subversivo propiamente hablando es el cambio de función de la expresión musical. Ya no se fingen pasiones, sino que en el medio de la música se registran emociones indisimuladamente corpóreas del inconsciente, shocks, traumas. Atacan los tabúes de la forma porque estos someten tales emociones a su censura, los racionalizan y los transponen en imágenes. Las innovaciones formales de Schönberg estaban emparentadas con la modificación del contenido de la expresión. Sirven a la irrupción de la realidad de este. Las primeras obras atonales son protocolos, en el sentido de los protocolos oníricos del psicoanálisis. (Adorno, 2003, p. 43).

20 Schönberg prefería el término «politonal». 
El cambio «subversivo» de Schönberg, en cuanto a la expresión musical, establece una diferencia importante con la música de Debussy. Las atmósferas de los preludios para piano (19091913) son una muestra de cómo el compositor francés pone en contacto al oyente con lo sensorial o sensible, lo que justifica su habitual asociación al impresionismo.

Como señala Adorno (2006) en otro de sus escritos, respecto de la relación de continuidad entre la etapa atonal y la etapa serial, los nuevos principios «llevan a la autoconciencia lo que ya se hallaba latente en la emancipación de la música respecto de los límites de los sistemas de referencia tradicionales» (p. 70). En la Segunda Escuela de Viena, la atonalidad surge de la eliminación de jerarquías, a través de una constante circulación del total cromático; la emancipación discursiva de la disonancia, que iguala la función consonancia-disonancia; y el uso intenso de disonancias duras (segunda menor o séptima mayor), dentro de una rítmica atonal o con acentos desplazados. La coherencia en una obra está dada fundamentalmente por la presencia de elementos aglutinantes, como la recurrencia a alturas e intervalos fijos.

En este contexto, la exploración de la variable tímbrica, que pone en juego la tradicional jerarquía del parámetro altura, incide en nuevas técnicas de ejecución de los instrumentos y de emisión vocal, como el canto hablado (sprechgesang). Asimismo, incide en la introducción de la melodía de timbres (klangfarbenmelodie), cuyo antecedente es posible encontrarlo en el principio de «división de la melodía» empleado por Wagner, donde una línea melódica se instrumenta de tal manera que los sonidos que la conforman se descomponen en timbres sucesivos (Adorno, 2006). Dicho con otras palabras, se trata de la distribución de los sonidos de una melodía entre varios instrumentos, utilizando sobre todo el fundido más que la cisura. Todos estos recursos son también utilizados por Webern y Berg desde su etapa atonal.

La composición mediante el método dodecafónico parte de la creación de una serie que involucra a los doce sonidos de la escala cromática. Esta serie constituye el material sonoro de una 
pieza y funciona bajo la regla de que los sonidos deben de ser utilizados — horizontal (melodías) o verticalmente (sonidos superpuestos o acordes)-, con rigor, de acuerdo con un orden preestablecido, evitando el surgimiento de un centro tonal por recurrencia. De esta forma, se produce la emancipación de los sonidos individuales respecto de su acorde, en términos de la tonalidad (Adorno, 2006). A lo largo de una obra, la serie puede manejarse utilizando procedimientos contrapuntísticos, como retrogradación, inversión interválica o inversión retrogradada; también puede ser dividida en grupos o transportada, lo que significa mantener los mismos intervalos melódicos entre los sonidos de la serie original, en un nuevo ámbito diatónico. En el serialismo dodecafónico, según Adorno (2006), derivado del principio dialéctico de la variación, convergen el uso del total cromático y el orden riguroso, de manera que las relaciones jerárquicas de los sonidos o grados de una escala son eliminadas por completo.

A diferencia de Webern; quien se radicaliza al plantear una destrucción progresiva de la herencia romántica tendiente a «rehabilitar el poder del sonido» (Boulez, 1952), lo que incluye la sublimación del despojo de toda retórica redundante; Schönberg se orienta más a la descomposición del orden tonal. Por este motivo Webern se convierte en el principal referente de la Nueva Música, durante la segunda postguerra. En este nuevo contexto, el método serial creado por Schönberg se radicaliza en manos de la llamada Escuela de Darmstadt (integrada por Boulez, Luigi Nono y Karlheinz Stockhausen, entre otros) al hacerse extensivo a todos los parámetros musicales, bajo el nombre de serialismo integral.

Los diferentes universos estéticos o estilísticos que se concentran en el cambio de siglo, sin lugar a duda, enfrentaron al oyente con una nueva realidad. La tonalidad se había encargado de preservar a lo largo de varios siglos una identidad musical que mantuvo al oyente en un espacio de confort. Las vanguardias modernistas lo obligan a salirse de ese lugar y a establecer 
conflictivamente un vínculo con la nueva música, así como a sensibilizarse ante los múltiples desafíos sonoros que surgirán a lo largo del siglo XX, en pleno diálogo con el pasado.

Finalmente, resta abordar la siguiente pregunta: ¿qué vínculos es posible vislumbrar entre los cambios en las composiciones musicales de Schönberg en los comienzos del siglo pasado en Viena y el psicoanálisis que estaba gestando Sigmund Freud? Es más, ¿qué cambios se producen en la escucha a partir Schönberg y Freud ${ }^{21}$ En el trabajo ya mencionado, François Dachet (2008) estudia en profundidad la forma en que se suceden las innovaciones en la escucha a partir de Freud y de Schönberg. Mínimamente desatacaremos dos aspectos en común: ambos vivieron en Viena en el mismo tiempo y caso es una palabra compartida entre el «caso Schönberg» y los «casos freudianos».

Por una parte, la expresión «el caso Schönberg» se produce en la presentación de los sucesivos conciertos donde una de sus obras fuera interpretada. Es más, a lo largo de los años, los argumentos estéticos que vinieron a posteriori a justificar las manifestaciones ruidosas durante los conciertos se desplazan y se transforman.

Bajo el refugio de los juicios de los críticos se despega eso que se establecerá como el límite subjetivo alrededor del cual gira incluso a veces hoy la apreciación de la música contemporánea: ¿se trata de música? No se trata solamente de diferencias de «gusto», sino del límite subjetivo que llevará a producir el juicio que va a señalar la diferencia entre la «extrañeza» a la cual somete la escucha de una creación musical contemporánea y la «sensibilidad» que ella supone. Los juicios comportaron incluso la referencia a las normas admitidas de la música de la época que permanecieron como el eje de comparación: armonías originales, a veces bizarras, extraña atmósfera y encantadora sonoridad, algo descuidado, un toque literario, cuidadoso hasta la pedantería, etc. (Dachet, 2008, p. 12). ${ }^{22}$

Incluso, no se trata de novedades musicales las que produjeron la atención del público, «es la cantidad de disonancias»: «Malvado atentado contra las orejas», «anarquía completa»,

21 Sobre esta pregunta nos detuvimos en: Fernández Caraballo, 2015.

${ }^{22}$ Las traducciones del texto de Dachet del francés al español son de Ana María Fernández Caraballo. 
«terrorismo» esos eran los calificativos que recibió la obra de parte de la crítica (Dachet, 2008, p.

12). En palabras de Buch (2006) «la crítica estética deviene entonces una crítica moral».

El discurso cambia de orientación: es la exterioridad a la música reconocida y aceptada lo que está subrayado. Los documentos presentados por Buch permiten abordar cómo se construyó en su momento una «naturaleza de la música» para poner en comparación aquello que no aparece en dicha naturaleza. Se le reprocha a Schönberg el rechazo de la tonalidad. (Fernández Caraballo, 2015, p. 9).

... la idea de que, a lo largo de todo el siglo XX y hasta hoy, permanecerá siendo el argumento favorito de los enemigos del vanguardismo musical, a saber, que toda música no tonal es contraria a las leyes de la naturaleza. (Buch, 2006, p. $210) .^{23}$

Al respecto interroga Dachet (2008): ¿cuál es el efecto de la nominación «atonal»? y responde

que

Ella no solo respalda la apreciación ya citada del crítico según la cual la música de Schönberg es contraria a la naturaleza, sino que aún pone la escucha del público en un torbellino en cuyo interior ya no es posible liberar los principios de composición musical puesto en obra por Schönberg, su singularidad. (p.18).

Las composiciones de Schönberg basadas en el periodo atonal libre lo llevaron a un callejón sin salida, dado que requería de nuevos catálogos de material y de reglas para cada obra.

Luego de numerosos intentos, escribió a uno de sus discípulos en julio de 1921: «Hoy he realizado un descubrimiento que asegurará la supremacía de la música alemana durante los próximos cien años». En esa fecha desarrolló su método de composición dodecafónico a través del cual Schönberg creyó ser capaz de proponer una estructura interna teórica para cada obra. (Fernández Caraballo, 2015, p. 11).

23 Esa naturaleza capturada en una ley, analógica y no estructural es de ese modo un resurgimiento de la «música de las esferas», basada en una antigua doctrina que se mantiene vigente desde Pitágoras (VI a. C.) hasta Kepler (siglo XVII d. C.). Esta doctrina afirmaba que el modelo para la creación del universo estaba basado en el uso de las proporciones musicales; los cuerpos celestes producían sonidos que al combinarse formaban la llamada música de las esferas. De esta manera se presuponía una correspondencia o armonía en el orden natural, pero de una naturaleza arquetípica, aquella que ha sido creada y procurada por la divinidad, entre registro tonal, sensibilidad y orden del mundo. 
Las ideas sobre el atonalismo que se sucedieron respecto de Schönberg se pueden relacionar con otro futurismo, el futurismo ruso y sus reglas poéticas (Dachet, 2008), similares con los principios de escritura de Schönberg.

Aquellos que se encuentran expuestos en la poética de Roman Jakobson: esa proyección del eje de la metáfora sobre los de la metonimia, paralelos a la equivalencia sostenida por Schönberg de la armonía y de la melodía. Al tiempo donde era creada la expresión «música atonal», la crítica de la época no había ignorado completamente esta visión. «Simultánea y melódica» escribió Siegmund Piesling a propósito del Pierrot Lunaire en 1912 en las columnas del National Zeitung. (Fernández Caraballo, 2015, p. 11).

Por otra parte, como plantea Dachet (2008), el artista no solo se anticipa al psicoanalista, sino que pone a la crítica en dificultades:

Pero aquello que no está más en «la música de Schönberg» puede estar dentro de lo que se llamará «la envoltura» del caso Schönberg. A condición de acordarse de que, respecto de Freud, aquello que se llama ordinariamente caso es esencialmente la escritura de lo que en las formas de la transferencia no encontró dirección a lo largo de las sesiones y que Freud devuelve con un acto de escritura. (p. 14).

\section{Referencias bibliográficas}

Adorno, Th. (2003). Filosofía de la nueva música. Madrid: Akal.

Adorno, Th. (2006). Escritos musicales I-III. Madrid: Akal.

Buch, E. (2006). Le cas Schönberg. Paris: Gallimard.

Dachet, F. (2008). L'émancipation de la dissonance. A propos du Cas Schönberg d'Esteban Buch. In: Superflux, 2, mars, Paris: Éditions de l’Unebévue.

Danto, A. (1999). Después del fin del arte. El arte contemporáneo y el linde con la historia. Barcelona: Paidós.

De Assis, P. (2012), (Coord.). Pierre Boulez. Escritos seletos. Lisboa: Casa da Música, Centro de Estudos de Sociologia y Estética Musical.

Didier-Weill, A. (1999). Invocaciones. Dionisio, Moisés, San Pablo y Freud. Buenos Aires: Nueva Visión. 
Fernández Caraballo, A. M. (2015). Relaciones entre música y psicoanálisis: escucha y escritura de casos. En Fermentario, 9(2), diciembre de 2015, pp. 1-13. ISNN 16886151 http://www.fermentario.fhuce.edu.uy

Fernández Caraballo, A. M. (2010). La música al margen o fuera de la representación: entre lo audible y lo legible. En Memorias del $6 .^{\text {to }}$ Foro Latinoamericano Memoria e Identidad. Asociación Civil Signo, Unesco, Universidad de la Rioja. Montevideo.

Freud, S. (1914). El Moisés de Miguel Ángel. Tomo XIII. En Sigmund Freud. Obras completas. Buenos Aires: Amorrortu Editores, 1997.

García Laborda, J. (2004). La música moderna y contemporánea a través de los escritos de sus protagonistas: una antología de textos comentados. Sevilla: Doble J.

Hegel, G.W.F. (1991). Estética II. Barcelona: Península.

Kröpfl, F. (2006). Algunas reflexiones en torno a la música. En Revista de Filosofía, 20, agosto. Córdoba: Universidad Nacional de Córdoba.

Lacan, J. (1972-1973). El Seminario, Libro 20: Aun. Buenos Aires: Paidós, 1998.

Levi-Strauss, C. (1976). El hombre desnudo. Mitológicas IV. México: Siglo XXI.

Nietzsche, F. (1973). El nacimiento de la tragedia, o Grecia y el pesimismo. Madrid: Alianza Editorial.

Quignard, P. (1998). El odio a la música. Diez pequeños tratados. Madrid: Andrés Bello.

Villalba, A. y Fernández Caraballo, A. M. (2012). Con-dissonâncias: ato analítico, poesia y música. En Leite, N. y Milán-Ramos, J. G. (Eds.) EntreAto: o poético e o analítico. Campinas: Mercado de Letras, pp. 321-338.

(c) (i) $(9)$

Esta obra está bajo una licencia de Creative Commons Reconocimiento-NoComercial-SinObraDerivada 4.0

Internacional 